$R M x A C, \mathbf{5 3}, 44-46(2021)$

(C) 2021: Instituto de Astronomía, Universidad Nacional Autónoma de México

https://doi.org/10.22201/ia.14052059p.2021.53.11

\title{
EASTERN ANATOLIA OBSERVATORY (DAG): RECENT DEVELOPMENT IN 2019
}

\author{
Cahit Yeşilyaprak ${ }^{1,2}$ and Onur Keskin ${ }^{3,4}$
}

\section{RESUMEN}

El Observatorio de Anatolia Oriental (DAG) contendrá el telescopio infrarrojo más grande del mundo (4 m) y será el primer telescopio infrarrojo de Turquía. Éste se encuentra en la ciudad de Erzurum en la parte este de Turquía con una altitud de $3170 \mathrm{~m}$. Presentamos el desarrollo reciente de DAG hasta finales de septiembre de 2019.

\section{ABSTRACT}

Eastern Anatolia Observatory (DAG) will be the Turkey's largest $(4 \mathrm{~m})$ and first infrared observatory is located in Erzurum city at the East part of Turkey with an altitude of $3170 \mathrm{~m}$. We present the recent development of DAG until the end of September in 2019.

Key Words: telescopes

\section{SITE}

DAG will be an observatory in Erzurum/Eastern Anatolia/Turkey region at the location of Karakaya Tepeleri/Konaklı/Erzurum. The terrain of the region is constituted by a high altitude plato $5 \mathrm{~km}$ plus a mountain of $3155 \mathrm{~m}$ altitude and acreage of 2500 decares $\left(\mathrm{N} 39^{\circ} 47^{\prime} \mathrm{E} 41^{\circ} 14^{\prime}\right)$.

Transportation from city to the site is easy and is approximately $35 \mathrm{~km}$ and takes $\sim 47$ minutes by road. The site has more than 250 days of clear night, low humidity (up to $2-10 \%$, so Dry), certain prevailing wind direction (N-E, stable), low wind speeds (calm), low temperature values (up to $-35^{\circ} \mathrm{C}$ for winter, cold), low atmospheric inversion layer $(\sim 2600 \mathrm{~m}$, ideal $)$, iced thin snow cover $(<150 \mathrm{~cm}$, Dust-free) and Snow season on November - April, (consistent).

\section{INFRASTRUCTURE}

DAG's has a modern and reliable infrastructure.

\subsection{Buildings}

ATASAM building is in Ataturk University campus and is $\sim 1000 \mathrm{~m}^{2}$ with Technician, Observer and

\footnotetext{
${ }^{1}$ Atatürk University Astrophysics Application and Research Center (ATASAM), 25240, Erzurum, Turkey.

${ }^{2}$ Department of Astronomy and Astrophysics (ASA), Science Faculty, Atatürk University, 25240, Erzurum, Turkey.

${ }^{3}$ Department of Mechanical Engineering, FMV Işık University, 34980, Istanbul, Turkey.

${ }^{4}$ Center for Optomechatronics Application and Research (OPAM), FMV Işik University, 34980, Istanbul, Turkey.
}

Guest rooms and Labs. It has a fiber optic connection to the site and a $60 \mathrm{KW}$ UPS.

The service (prefabricated) building-1 in DAG site is a $\sim 100 \mathrm{~m}^{2}$ building. It is a temporary building and house security crew. It contains the technician's and observer's rooms. It has fiber optic connection to all buildings including ATASAM itself and a $30 \mathrm{KW}$ UPS.

The service (prefabricated) building-2 in DAG site is a $40 \mathrm{~m}^{2}$ building. It is also a temporary building with a technician's room. Fiber connection is also available in this building.

Atmospheric systems and Differential Image Motion Monitor (DIMM) tower in DAG site is a steel constructed tower with a height of $7 \mathrm{~m}$. It has a fiber optic connection and a $10 \mathrm{KW}$ UPS with numerous atmospheric and astronomical systems.

Aside the energy and snow vehicles garage near DAG site there is $\mathrm{a} \sim 300 \mathrm{~m}^{2}$ building. A 20 tons gasoline tank, a generator, transformers and a snow track can be found in this building.

\subsection{Electricity}

DAG operates with a 3 phases medium voltage underground lines. The length of line is approximately $4 \mathrm{~km}$.

\subsection{Power}

For now there is a 3 phase temporary power line in DAG which is supported by a 25 and a $10 \mathrm{KW}$ UPSs. 


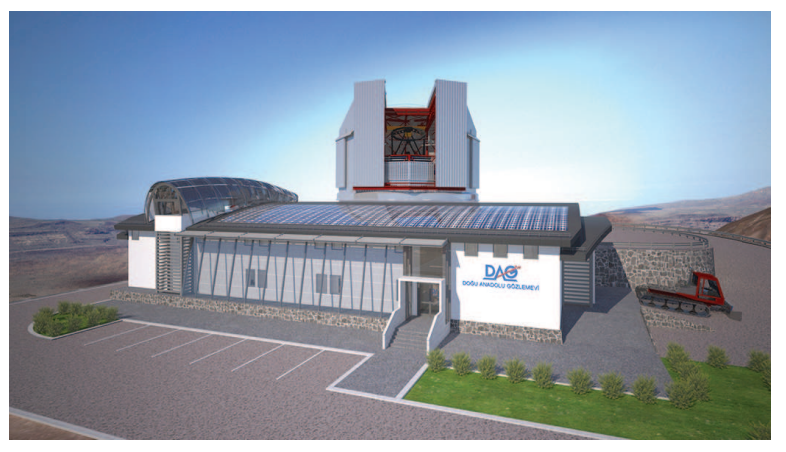

Fig. 1. DAG Main Building

The permanent backup power plan is constituted by $2 \times 120 \mathrm{KW}$ UPSs, $2 \times 400 \mathrm{KW}$ generators and $3 \times 800 \mathrm{KW}$ and $3 \times 150 \mathrm{KW}$ transformers near the DAG site.

\subsection{Lightning Safety}

There are 3 rods in DAG site to prevent lightning strike to equipment and buildings.

\subsection{Internet}

DAG uses a 48 cores/100 Gbps transmission fiber underground line. The length of the line is $\sim 30 \mathrm{~km}$ and connects ATASAM building to all real estate of DAG project. There is also a 24 Mbps Radiolink connection too working as a backup system.

\subsection{Transportation}

ATASAM building (Ataturk University campus) is $\sim 12 \mathrm{~km}$ away from the Erzurum airport and has an asphalt road. DAG site is $\sim 32 \mathrm{~km}$ away from Erzurum airport which has a $\sim 25 \mathrm{~km}$ asphalt plus $\mathrm{a} \sim 7 \mathrm{~km}$ stable road.

\subsection{Vehicles}

DAG uses two pickup's vehicles $(4 \times 4,2500 \mathrm{cc})$, an $\operatorname{ATV}(4 \times 4,800 \mathrm{cc})$, a snow truck $(500 \mathrm{cc})$ and a snow cabin truck $(5000 \mathrm{cc})$ for transportation.

\subsection{Seismic System}

There are 5 seismographs connected and spread around the DAG site.

\subsection{Geological Analysis}

DAG is located on Basalt ground. So far drilling has been done 20 times down to $10-50 \mathrm{~m}$. Water is considered to be found after $20 \mathrm{~m}$.

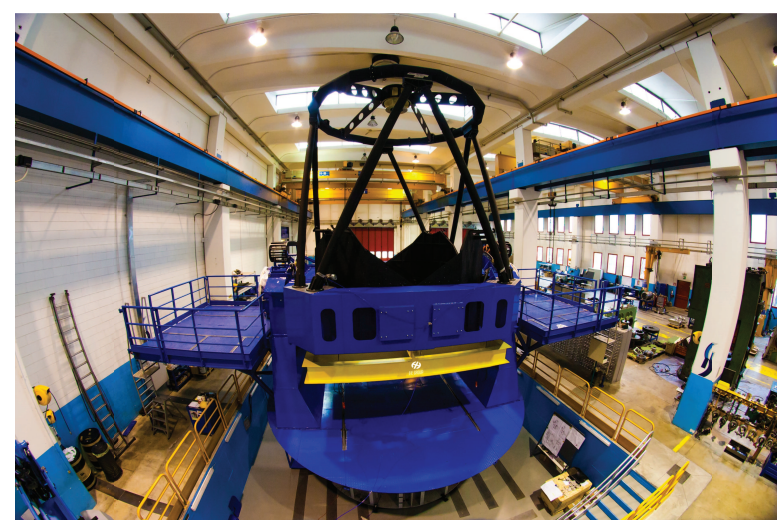

Fig. 2. DAG Telescope

\subsection{Water}

Two water sources were found near DAG site (1 and $1.5 \mathrm{~km}$ away at 3000 and $2800 \mathrm{~m}$ altitudes).

An artificial lake is located close to DAG at 2500 $m$ altitude which belongs to Konaklı Ski Center.

A filtered water tank with a capacity of 60 Tons is located in DAG site.

\subsection{Accommodation}

Ataturk University has 3 guest houses with 160 rooms and capacity of 300 people with a 3-4 star hotel standards.

ATASAM building can host 4 people with a 2 star hotel standards in its 2 rooms in Ataturk University campus.

The service (prefabricate) building-1 in DAG site with 3 rooms can host 6 people.

DAG telescope's main building will be able to host 12 people in its 6 rooms with 4 stars hotel standards.

\subsection{Security System}

There are 8 security personnel active at the DAG site and 5 night vision featured security cameras.

\section{BUILDING}

The design of DAG building was done by Arch. A. Erkan Şahmalı (GÜNARDA comp.). DAG has a passive solar energy, eco-friendly and disabledfriendly design, stairlift, concrete, and steel construction design. see Fig. 1.

\section{ENCLOSURE}

DAG has a rotating with a large slit door enclosure with a diameter of $16 \mathrm{~m}$, height of $18 \mathrm{~m}$, active environment control, cooling system, louvers and wind screen, bridge crane all designed and produced by EIE(European Industrial Engineering). 


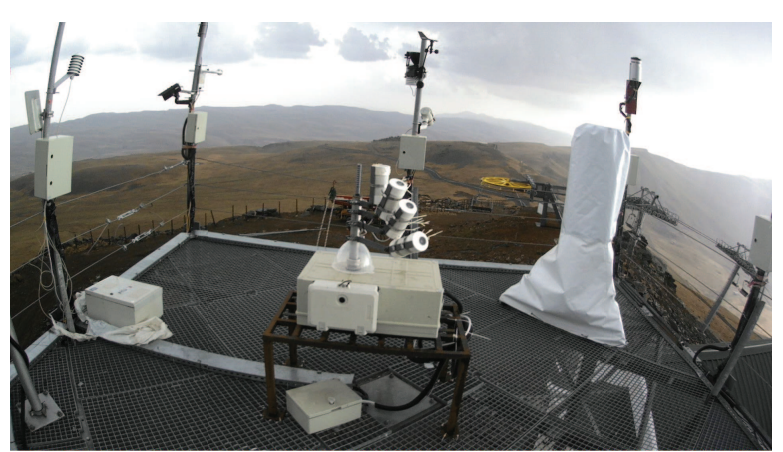

Fig. 3. DIMM Tower and the astronomical and atmospheric equipment

\section{TELESCOPE}

DAG telescope will be a $4 \mathrm{~m}$ class telescope with focal length of $56 \mathrm{~m}$ and focal ratio of 1.8. The main observational wave-band of DAG telescope will be in optical and NIR $(<3.0 \mu \mathrm{m})$. The telescopes field of view will be $30^{\prime}$ in Large - unvignetted and $10^{\prime}$ in narrow - vigenetted mode. see Fig. 2.

DAG telescope will have 2 Nasmyth platforms. One of the platforms will be equipped by adaptive optic system which we call N1 and the other will be a seeing limited platform with name of N2. Each platform has a large capacity. N1 will house 6 instruments: 3 in optical, 2 in near infrared wavelength and an adaptive optics system.
DAG telescope will be an altitude-azimuth mounted telescope with a Ritchey-Chrétien optical design and active optics (ao), adaptive optics (AO), derotator and field corrector. This telescope will have the highest performance in its class.

A zerodure (Schott) mirror with pointing of $<2^{\prime \prime}$ and tracking accuracy of $<1^{\prime \prime}(\mathrm{rms})$ designed by Dr. Laurent Jolissaint (HEIG-VD) and a narrow field plus a ground layer adaptive optics designed by Dr. O. Keskin (OPAM) and manufactured by AMOS\&EIE will form the DAG telescope.

\section{METEOROLOGICAL \& ASTRONOMICAL SYSTEMS}

An AWOS, DAVIS, Vaisala meteorology station aside a Boltwood Cloud Sensor and Meteosat System and a GNSS station for PWV calculation constitute the system used for meteorological observations.

Tow All Sky Cameras, 4 Sky Quality Meters (Automated Rotational Sky Quality Meter, R-SQM) and a MASS-DIMM system are located at DAG site and are operational. A SLODAR (Slope Detection And Ranging) system will be placed in the site on 2020.

Acknowledgments: This study is supported by DAG Project (Project ID: 2011K120230), Atatürk Universtiy and ATASAM. Authors are grateful to DAG Project, Atatürk Universtiy and ATASAM for continuous and valuable supports.

\section{REFERENCES}

Dogan, E., Ozbaldan, E. E., Shameoni, N. M., \& Yesilyaprak, C. 2016, RMxAC, 48, 31 